\title{
Lived Experience of Online Teaching During the COVID-19 Pandemic: Implications for Curriculum and Teaching
}

\author{
Peshal Khanal, \\ Peshal.khanal@tucded.edu.np \\ Associate Professor \\ Central Department of Education \\ Tribhuvan University
}

\begin{abstract}
As the COVID-19 pandemic has affected all sphere of human life and the schools across the country are closed due to the risk of spreading the virus, online teaching has become a major alternative pedagogical strategy among the private schools in particular. This article reports a study that explores how private school teachers perceive and adopt technological learning, how they transfer their technological knowledge and skills into the online classroom and how they self-assess their practices. This is done through a phenomenological study focusing on the meaning the participants make from their lived experience on 'technological learning and application' in the face of the pandemic. The study found that dealing with uncertainty and fear of the COVID-19 and the additional pressure for doing online teaching amidst the crisis evoked frustration and anguish among the teachers. Despite a number of challenges and crisis, teachers, however, learn to deal with the technological challenges and manage to run the class through virtual mode. Nevertheless, they assess the online delivery is not effective due to the various constraints. The study suggests for ensuring the access of ICT resources and facilities to both teachers and students, sufficient training to the both groups and digitalize curricular materials for the effective implementation of virtual learning.
\end{abstract}

Key Words: online teaching, COVID-19, pandemic, phenomenology, Nepal

\section{Introduction}

Online teaching has become a widespread remedial approach to support the student learning in the times of school closure due to the COVID-19 pandemic. In Nepal, private schools in particular have pushed teachers to teach their students online using web applications such as Microsoft Teams, Google Meet and Zoom. This article explores the essence of being an online teacher as first-time experience in teaching career through the lived experience of the four participant teachers. The main objective of this phenomenological study is to answer the question 'what is the experience of being online teacher in the times of COVID-19 crisis'. Four teachers, two males and two females, who went through the first-time experience of online teaching amidst the school closure due to the COVID-19 pandemic were participated in this study. In specific, this study assesses how urban private schools in Nepal putting pressure to teachers for 
learning skills of e-pedagogy and switching to online teaching as a response to the crisis created by the COVID-19 pandemic and how primary school teachers are coping with this learning and implementing situation. The focus is to look into how this forced and sudden adoption of technology-driven teaching affect personal, social and psychological well-being of teachers and what implications can be drawn for both the government looking after the school education and school administrators.

\section{Context}

The COVID-19 pandemic has brought unprecedented challenges in all spheres of human life across the globe. The educational sector remains no exception. The pandemic has caused the closure of schools globally, with more than 1.57 billion children $(90 \%$ of the total enrolled students) from more than 190 countries being unable to attend their regular classes ${ }^{1}$ (UNESCO, 2020).

Like most parts of the world, Nepal imposed a nationwide lockdown and closed all educational institutions across the country since 24 March 2020 as a measure to limit the spared of the COVID-19 virus. While schools did not conduct any formal teaching in the first month of the lockdown abiding the government's guideline to the pandemic, some elite private schools took initiatives to run online classes beginning from late April 2020, the starting month of Nepali academic year. And soon online teaching grew as a fashion among all urban private schools claiming this new approach as the best transitional remedies of the learning crisis created by the pandemic.

As uncertainty continued along with the exponential growth of COVID-19 virus almost across the country even after the complete lockdown over two months, the Ministry of Education in Nepal endorsed a guideline on $31^{\text {st }}$ May 2020 to facilitate student learning through the alternative system (Ministry of Education, 2020). This guideline allows educational institutions to run classes and organize lessons through radio, television, personal computers/smartphone and Internet addressing the diverse needs of the students. The Ministry has begun formal broadcasting of remote lessons from Grade 1 to 10 from FM radios and televisions since $15^{\text {th }}$ June 2020 . The Ministry's guideline encourages educational institutions to plan for a more flexible and differentiated delivery approach through all means such as radio, television, computers (offline) and the Internet. However, almost all private schools have opted for online teaching, and the proliferation of this internet-based delivery extended up to the pre-primary or kindergarten level. Most of these schools have been using free versions of video chat rooms provided by Zoom and Google to run the class while a few others have used Microsoft's Team - a licensed product, for this purpose. These schools run very quick and short training sessions to teachers, mostly online, focusing mostly on the features of the online platform, video conferencing apps, registration procedures to the system and delivering lessons through the new technology. This unprepared and hasty shift to online teaching raised questions not only about the effectiveness of online teaching itself but largely about the ways the technology is learned and adopted by the teachers and the ways the learning is delivered through this mode.

1 This data was published in April 172020 by UNESCO (see update data at https://en.unesco.org/ covid19/educationresponse) 
Lived Experience of Online Teaching During the COVID-19 Pandemic: Implications... $/ 91$

While the adoption of online delivery to reach out to students in the times of the COVID-19 crisis has been prevalent in every corner of the globe, this is found more sustained and effective at the higher education level (Bao, 2020; Johnson, Veletsianos, \& Seaman, 2020). In the particular case of Nepal, the university system has already acquired some form of online, or at least a hybrid, pedagogical system, and a significant number of the faculties are trained to use the computerand internet-based technology in teaching. However, except for a few exceptions, this kind of virtual delivery system was totally new to the school education in the country. A considerable gap exists in the literature about the ways transitional online pedagogy is internalized and adopted by the teachers in the school system in particular. In this context, this article explores how primary school teachers perceive learning and implementing online teaching in the time of the COVID-19 crisis. This was done listening to their lived experiences of teachers about the central phenomenon of 'technological learning and transformation of this learning through the online classroom'. In specific, I focus on how primary school teachers perceive and adopt technological learning, how they transfer their new learning into the online classroom and how they self-assess their practices. In this way, I explore how their personal, idiosyncratic experiences provide insight into the reality of the so-called technological remedies to learning loss in the crisis times of COVID-19. The key questions are as follows:

- How do teachers experience of hasty and sudden preparedness and learning of technology for online teaching in a response to the COVID-19 crisis?

- What complexities and challenges teachers face while switching from the face-to-face to virtual teaching?

\section{Transitional pedagogy during the COVID-19 pandemic: A literature review}

While the literature on how the countries around the globe are putting efforts on using online and other transitional strategies as a means of remedial learning are emerging (e.g. Zhou, Li, Wu, \& Zhou, 2020; Morgan, 2020; Pace, Pettit, \& Barker, 2020), most of them provide status and challenges of the transitional pedagogies based on the policy review and survey. Zhou, Li, Wu and Zhou (2020); Zhou and Li (2020); and Zhang, Wang, Yang, and Wang (2020) for example, provide a broader overview of China's large-scale online strategies - School's Out, But Class's On, clarifying how this large-scale campaign is guaranteed by its technological foundation and what impact this has made on the reconstruction of ecological educational models in China. Several other articles throw light on how this large-scale reform has been understood, contextualized and implemented in the local school contexts (e.g. Dai \& Xia, 2020; Xia, 2020; Xie \& Wang, 2020; Dai \& Lin, 2020; Zhao, Zhou, Liu \& Liu, 2020). Some scholarship provides insights from the guidelines and provisional strategies for using online teaching in the time of crisis. Morgan (2020), for example, provides some reflective summary of the International Society for Technology in Education's guidelines on how to use remote education to benefit students during the COVID-19 pandemic. The major suggestions drawn from this guideline are to provide effective online education, ensure equity, communicate expectations clearly, provide student-centered learning, use free high-quality resources, and respond to the emotional toll.

Similarly, coining a new term - quarenteaching - Pace, Pettit, \& Barker (2020) offer some useful tips and resources for the rapid transition to online instruction, emphasizing collaboration, 
differentiation, and personalized learning. With suggestions for creating a positive culture for purposeful learning, they conclusively call us to "hang on to what we know is important for learning - organization, positivity, purpose, and engagement - as we journey into this new environment, perhaps the task will be less like slaying a dragon and more like discovering a whole new world" (Pace, Pettit, \& Barker, 2020, p. 9). A survey conducted by Johnson, Veletsianos, \& Seaman (2020) among 897 faculty and administrators at 672 post-secondary institutions in the United States provide some pictures of online teaching in the country. The results reveled that almost all institutions transitioned to emergency teaching and learning approaches in the form of some online, remote learning. The survey suggested that most of the transitional measures are ad-hoc with limited remedial teaching where "the higher education sector experienced differed from a planned online learning experience; even experienced online faculty used new teaching methods to cope with the challenges presented due to this mass-scale pivot". While technology is used widely across the globe for remote learning, its proper management and utilization has always been a concern. A recent survey conducted by OECD among 330 people working in the education sections in 98 countries revealed that the availability and management of technological infrastructure is a major challenge in the transitional pedagogy, with only 38 respondents $(8.7 \%)$ said that there is no challenge at all in both access and management of the technology (OECD, 2020).

Few published works provide some critical views on the technology-supported remote teaching during the COVID-19 pandemic. Perrotta and Bohan's (2020) experiences of online teaching at higher education level, for example, are mixed, suggesting online teaching leads to an increased feeling of isolation from students, inconsistent teaching evaluations, and varying degrees of academic freedom. The results of Lansangan's (2020) autoethnography on their collaborative effort of online learning in the times of COVID-19 crisis is somehow encouraging. With a reflection on the effectiveness of collaborate approach of learning, Lansangan highlights that "the consistent communications and collaborations among the students, parents, and teachers ... built a knowledge-sharing community and realized that everyone's shared roles make the adjustment of the educative process smoother towards an undisruptive learning" (p. 29).

The works of Dube (2020) and Mengistie (2020) underscore the issues of social justice while adopting the technology-driven remote teaching during the COVID-19 pandemic, particularly in the low-income regions. Referring to the South African government's recent move to adopt online learning as the main alternative during the COVID-19 pandemic, Dube (2020) reveals that many rural learners in South Africa are excluded from teaching and learning due to a lack of resources to connect to the internet, the learning management system, and low-tech software. The core message of this article is that while COVID-19 pandemic has created, if not widened the gap between the rich and the poor, or urban learners and rural learners, any form of transitional approach to education during the time of COVID-19 should not violate the rights of learners, despite their geographical location. With a similar tone, Mengistie (2020) provides a situation of transitional online teaching in Ethiopian higher education which excludes almost $80 \%$ of university students who are rural-based without electricity, laptop, smart-phone, desktop, and internet. Similarly, the country's nationwide radio program could not involve a large section of school-going children due to the problem of access to electricity and radio. Mengistie (2020) 
highlights that elite centered provision of learning is haphazard which "may arouse emotional and psychological problems in both types of students who are accessible and non-accessible to it" (p. 149).

Reviewing the literature about the transitional teaching measures in the times of COVID-19 pandemic suggests that any approach to teaching and learning during the time of crisis should not necessarily be the same, generalized and prescriptive. Rather, the remedial approach should be assessed based on the extent to which resources are available, culture is supportive and the actors in the system are prepared to deal with the complexity. The dominance of the top-down policymaking and prescriptive approaches of schooling in emergencies may overlook the very nature of more localized and context-specific needs and practices as well as the idiosyncratic characteristics of actors in terms of their readiness and abilities to put the new ideas into practice. In this context, studies grounded in the local setting, looking how the culture, resources and practices have bearing on online teaching in the time of emergency and crisis, provide a greater insight into the underlying realities, nuances and complexities of such approaches and, such works, some ways, fill up the existing gaps in the literature.

\section{Method}

This study is based broadly on a phenomenological design, focusing on the meaning the participants make from their lived experience on 'technological learning and application' in the face of COVID-19 pandemic. In this way, I want to draw the lived meaning of the experiential moment of the technological learning and application itself (Adams \& van Manen, 2018). I purposefully work with four teachers who have attended a short training to use the web-based applications such as Zoom and Google Meet for teaching primary school children (grade 1-5), and during the time of the interview, they have been taking regular online classes using these technologies. These teachers are working in two different private schools (School A \& B) in Chandragiri Municipality, Kathmandu, both running classes from Nursery to Grade 10. These two schools began their online classes from early April 2020 through Zoom and Google Meet. All four teachers hold Bachelor's degrees, one specialized in mathematics, two social studies and one in English. Although these teachers were literate in computer skills, none of them had received any form of specialized training in computer skills before the pandemic broke out in Nepal. Notably, both schools did not have provisions to use computer technology such as overhead projectors and PowerPoint presentations in their regular face to face classrooms, though some teachers used technology voluntarily in the secondary grades.

I had an early familiarity with the teachers as we all belong to a small community near to these two schools. Being myself a teacher at Tribhuvan University, I used to have informal talks with them about the general issues of education and teaching, and most of the time, I used to be available to their needs. The idea of this study came to my mind when a teacher among the four who resides close to my house called me with her worry for preparing ppt slides and teaching primary children through Zoom. To my wonder, she shared how she was forced to learn and use the technology with a quick but little support of the school. As I started helping her and became more inquisitive to learn her learning struggle, she shared other teachers in the community were also struggling on the same matter. In this way, I came in contact with all four teachers. Initially, 
I listened to their concerns and helped them in sorting out their problems, and gradually I talked to them, mostly individually, about their experiences of learning technologies and applying in their online classes.

I particularly focused on the shared or common experiences of the participants about the phenomenon (Creswell, 2007), being very open to the phenomenon and 'seeing through my fresh eyes' (Finlay, 2012). As a phenomenological strategy of bracketing, I suspended my natural attitude and taken-for-granted assumptions and set aside my personal biases and judgements over the technological learning and application (Finlay, 2012). I tried to dig out their 'examples' about what they encountered and did, as 'examples in phenomenological inquiry serve to examine and express the exemplary aspects of meaning of a phenomenon' (van Manen, 2017, p. 814). Along with my unstructured interviews, the participants sometimes shared what they were doing and dealing with the technologic, which helped me to "move beyond what the participants say of experience to what is revealed in the telling" (Finlay, 2012, p. 180). This approach helped me find ways to access that unfolding as things appear. I recorded most of the one-to-one conversation and wrote fieldnotes capturing those that could not be recorded. I transcribed and coded the interview and field notes, and summarized the codes into a few core themes.

The collection and explication of the participants' information and voices, major meaningmaking units, went hand and hand, and accordingly, the analytical process went inductively from the first interview. I transcribed the interview as soon as I completed the interview. When I transcribed the interview, I took notes what came into my mind and this was communicated, clarified, verified in the subsequent interviews with the same and other participants. The interviews, in fact, were formed as a dialogue between the participants and me and the iterative process of dialogue with communicating and verifying the emerging themes and the underlying meanings 'co-constructed' the understanding of the phenomenon. The themes were analyzed and interpreted using the thematic analysis approach (Braun \& Clarke, 2006).

\section{Findings and discussion}

Initial frustration and struggle

Dealing with uncertainty and fear of the COVID-19 and the additional pressure for doing online teaching amidst the crisis evoked frustration and anguish among the teachers which gradually faded with adjusting with the new working environment. All four teachers shared their first thought was to 'opt out' from online teaching as they were not mentally prepared to take up this responsibility, nor were they equipped with the technological skills required for this task. A teacher shared, the dilemma of 'quitting' or 'learning and surviving' was painful because the opt-out choice could have a long-term consequence for her survival and job security. To all teachers, learning technology and using it for online teaching has not been a choice, but an approach to rescue and save the job in the COVID crisis. Although the school authorities did not expect from teachers to have skills to do teaching online before the crisis, they asked teachers to learn and prepare themselves if they wanted to remain in the job. A common experience of the participants was that online teaching demanded a number of skills and they were not equipped themselves with adequate knowledge and skills to do virtual teaching confidently. And without 
Lived Experience of Online Teaching During the COVID-19 Pandemic: Implications... 195

acknowledging teachers' readiness, the authorities forced them to start the teaching. Their lived experiences of 'fear', 'anxiety', 'pressure' due to 'unpreparedness'

However, teachers started doing online teaching with very little knowledge, skills and experiences and they found themselves on a very weak foundation. In the words of a teacher, asking her for online teaching of little children is similar to asking a person to drive a public bus with full passengers who lack experiences and knows very little about how to drive. The teachers were doing something that they are not fully prepared and fully confidence with. The school authority asked the teachers to start online teaching with little exposures and training and if the teachers became unable to do it they were held accountable to themselves. "one day, the head teacher called me and said the school was going to start the online teaching and asked me to contact the students and make them ready for the online teaching.

Job security and 'privateness' are the common terms echoed in the teachers' voices particularly on the arguments for joining to the teams of online teaching. The job in private schools is safe as long as teachers can work under the broader interest of school owners. As the COVID-19 crisis required schools to retain students by teaching them through some alternative means, private schools choose teaching them online using some virtual applications such as Zoom or Google Meet. This has created a situation that made teachers feel that one cannot rely on the job in private schools as the authority may fire them anytime providing some reasons of their inability to work in the changed and difficult situation. A teacher added:

"I could not say 'no' to my head teacher's call to start online teaching as they could fire me if I showed my reluctance to them. Had I been a teacher in a government-aid school, I could say it takes time for me to learn and start".

The school authority did not care if the teachers are prepared, resourceful and ready to teach in online setting. All the participants shared that the school authority had an attitude that teachers should responsible for equipping themselves with required knowledge, skills and resources. In a response to one participant's worry about the lack of preparedness and resources to do online teaching amidst the psychological fear of the pandemic, his head teacher said, "I don't care whether you are prepared or not, but you should do it anyhow if you want to remain in the job". Other teachers also shared similar experience. "Sink or swim, this is your decision. You have to do it".

The virtual training for the teachers to prepare them for teaching online was not enough. The training was provided them to download the zoom, its basic features, the screen sharing techniques. "I had no prerequisite knowledge on ICT and computer skills, I learnt nothing in the training. I did not have opportunity to do practice. This was a piecemeal", said a teacher. When they asked for a longer training, with step-by-step instruction, the school refer them to use YouTube video to ask them to learn themselves.

The teachers' experience on the attitude and behavior of the school authority was not supportive, friendly and humane during this time of crisis, as teachers were expecting more flexible and 
supportive role on the part of the school administrators. However, the authority did not care the wellbeing and readiness of teachers to carry out newer approach of teaching. A teacher shared,

I was expecting that the school authority would regularly communicate with us, taking care of our physical and psychological wellbeing during this difficult time. But contrary to my expectation, the head teacher sent a message in our teachers' group, informing us to contact our students and start lessons through Zoom from the next week.

This experience suggests that teachers' wellbeing and readiness is a key requirement for them to undertake a new approach of teaching in the difficult time. A good communication between school authority and teachers is essential to make both parties understand the realities and underlying challenges associated with the virtual teaching. Teachers' are overburdened with not only learning and doing virtual teaching, but also with the ways schools add tasks one after another during this crisis. Teachers are also asked to trace contact of the students not joined in the online class. A teacher showed a message in her mobile. "A Viber memo to our group by head teacher was like this - This is your responsibility to contact students and bring them in the virtual class". While the school is forcing teachers to contact students, train them to use online technology using smart phones or laptop whatsoever they have, and teach them in the virtual mode, teachers take this responsibility as a 'must-do' responsibility, which otherwise could risk the continuance of the job in the school.

\section{Hope amidst resource constraints}

The learning and teaching through virtual application have been grossly affected by the resource constraints on the part of teachers and students. The major constraints include frequent power cut, ineffective internet, and lack of devices such as smartphones and laptop. Among the four teachers participated in this study, two did not have their personal laptop and desktop computer. They were using their mobile phones for learning and teaching. Only two had a Wi-Fi connection at their home. Other two were using data pack on their mobile phone, which is costlier than regular connection. While teachers lack technological devices and resources for online teaching, the need of such resources for the whole family is making the problem worse. A teacher said,

Everyone needs a machine now at home now. My children (one son and one daughter) are also taking online class. My husband is also working from home. We have two mobile phones and one laptop. When we all need at a time, either son or daughter would miss the class.

Despite of the fact that teachers did not have adequate resources, they were doing online with the whatsoever resources they have. And, although they experienced a sense of frustration at the early days of their online teaching, they became gradually able to cope with the problems and overcome the challenges. A teacher added, "I did not have laptop. I used my Samsung phone which was not easier to follow every instruction. There were no buttons as shown by the instructors. Just I listen. However, I could manage." As the teachers gradually got into the technological learning, they become hopeful and encouraged to manage the problems related to the access and availability of devices and technology. A teacher has this to say, 
Initially I was totally frustrated because I had no knowledge of using laptop and mobile apps for online teaching. Later as I had no other choices, I tried to learn using mobile apps and laptop from my husband. And, gradually I became able to use both devices. I started using my husband's laptop when he was not working on it. When I used laptop, I felt comfortable. Using mobile phone, I just delivered lectures.

The transformation of teachers along with their learning and using technology in fact is strengthened by their motivation and self-help practices. Teachers tried hard to equip themselves with necessary resources and skills by being a life-long learner, a strategy to learn from friends, family members, YouTube and internet sources. This is the process through which teachers feel empowered despite the uncertainties amidst the pandemic. A teacher added:

Although schools did not provide us any support for virtual learning, I tried myself to learn from multiple ways and means. I learnt from my daughters and friends, watched YouTube video and tried my best to learn how to best deliver lessons through online.

The boosting of teachers' confidence on learning and using technology during the crisis is remarkable. While most of the teachers were very much unknown about the use of technology for online teaching at the initial stages of the pandemic, this crisis became an opportunity to learn and use technology and secure the job. As most of the private schools used online teaching through Zoom and Google Meet immediately after the government introduced a guideline for alternative ways of teaching during the crisis, most of the teachers had no options other than learning technology in order to secure their job. A teacher has this to say, "I had to face a "do or die' situation. Because if I did not prepare myself for using technology and do online teaching, I would risk my job". This means, although teachers had a very tough time during the early phase of the pandemic, with a fear of the pandemic as well as the job-related crisis including the disruption of monthly salary, they took this crisis an opportunity to equip themselves with technological skills and use them through online teaching. A gradual shift in learning of ICTs and their application boosted their confidence and they became enthusiastic and hopeful for bringing further innovation and change in their traditional teaching.

\section{Complexities and challenges}

The first challenges teachers faced is related with the access to the resources and lack of opportunity to learn new skills. Most of the teachers lacked personal laptops and computers. While the schools informed teachers to manage laptops and computers on their own for the online teaching, this was the first challenges teachers faced during the pandemic. And, as the schools did not provide them with their regular salaries, teachers became unable to purchase new machines for teaching. Teachers' initial motivation faded as the schools informed them that the teachers should manage the required resources for online teaching themselves. A teacher shared, "My schools did not provide us with required resources for online teaching. We had an expectation that the school would provide us not only the resources required for online teaching, but also sufficient training for digital skills." 
While most of the teachers were using smartphone for their personal purpose, they first met the resource constraints using their smartphone for their online teaching. Using smartphone for Zoom or google Meet is difficult to use as this feature has minimum system to support power point presentation and sharing other files. A teacher shared, "I did not have my own laptop. So, I used my mobile for online teaching. But using mobile phone, I could only deliver lecture to the students." Another teacher said, "I had learnt to prepare power point slides and share through Zoom, but because I did not have my personal laptop or computer, I could not use it for online teaching." This shows that although teachers were motivated for using multiple strategies of online teaching, lack of adequate resources and facilities remained a key problem.

Requirement of multiple devices at home for children and parents is another constraint. As online teaching became a major strategy of most of the private schools, teachers also required devices for their children to take their regular virtual classes. A teacher shared, "I have two children taking online class. I am also teaching through online. My husband works from home online. We have only 2 devices. We could not allow our children to take all classes. They could take when we are free." Similarly, teachers also faced problems regarding the speed and cost of internet while doing online teaching. A teacher has this to say, "My Internet frequently gets disconnected and while I rejoin through using data, many of my students are already disconnected." Teachers also faced problems regarding the cost of equipment and internet in the time when their regular salary is discontinued. A teacher adds, "I have no salary for four months and I am facing hardship for managing my everyday life. How can I then buy laptop and Wi-Fi? So, I am using my mobile phone and using data for the internet."

Teacher also faced problem regarding the student's regular presence in the virtual classroom. Many of the students do not aware of features of Zoom or Google Meet, nor their parents. As a result, the online class is very noisy and ineffective. A teacher shared, "Many students do not know how to mute the device while delivering the lesson. They are not able to follow my instruction. In addition, students' regularity is another concern. A teacher shared,

Most of the students take online class through their parents' mobile phone. One day they appear, and another day they disappear. We are asked to call their parents about their absence. When I call parents about student's not coming in the virtual class, the frequent answers are like - no electricity, internet did not work, no device for every child at home.

The teachers experienced that student's irregularity and inability to use the Zoom or Meet properly has made havoc to the class. While teachers asked parents to send their children regularly in the online class, parents shared their own problems and stories. In other words, teachers faced problems not because of their resource constraints, but also due to the problems faced by the parents. An anecdote from a parent below is an example:

I plan every day for my three children to take the online class as we have two devices at home and their classes overlap frequently. So, one child misses a class one day. This creates a family disputes at home. We are hardly managing this. Even then, this is ineffective at all because my children said they are not learning. 
The teachers also shared that they do not have a conducive working environment at home as they have to deal with multiple things at home. Furthermore, some elderly family members do think that this taking online class is a luxury, not a job. For them, sitting in front of computer or laptop or using smartphone is just a fun. A female teacher has this to say,

Taking online class from my room is always chaotic as my children and parent-in-laws frequently entered into my room and asked what I am doing. They do not take my work seriously as if I am doing some fun. For my parents-in-law, I am in holidays due to COVID.

The experiences of teachers show that the online teaching is more a formality, than real teaching. Because of several problems such as access, connectivity, lack of experience of using online learning devices, ineffective interaction, poor learning environment at home, parental illiteracy over ICTs.

\section{Implications for curriculum and teaching}

This study has suggested a few implications for curriculum and teaching. Firstly, the sudden and hasty introduction of virtual teaching shows a long-term plan is needed to support schools and teachers in order to prepare them for online teaching. The fundamental requirement is that schools and teachers are to be equipped with adequate ICT infrastructure and resources. This requires a significant investment from the government. The schools could mobile their internal resources if they have. The private schools should ensure that they have adequate ICT facilities and resources. This should be a prerequisite for running the academic program. Next, teachers should be provided opportunity for upgrading their knowledge and skills in ICTs through regular in-service training programs. The upskilling of teachers in ICT should be a core component of their professional development programs. The COVID pandemic has made every teacher aware of the very need of alternative mode of delivery particularly during any kind of unforeseen crisis. In addition, this pandemic has also provided the teachers with opportunity to learn and use of ICT for virtual teaching. This should be continued through some concrete plans and programs.

Another implication of this study is that curriculum and curriculum materials should be designed in such a way that support the online delivery of the learning easily and effectively. This means, each learning content and practice materials should be digitalized. In addition, teachers should be oriented to prepare the learning materials digitally. The curriculum should be detailed out in such a way that each learning outcomes and related learning experiences are elaborated that help teachers to select appropriate activities for the students in the virtual forum. The curriculum and teachers' guide should provide alternative instructional strategies that help teachers to use curriculum in a condensed way in the time of crisis. 


\section{Conclusion}

This phenomenological study raises critical issues of integrating ICTs in teaching and use of online as an alternative means or strategies of teaching and learning. Importantly, the hasty and sudden application of ICT and use of online delivery is questionable as there are several issues to sort out before introducing such transitional measures. First, it is the utmost important to ensure the access of ICT resources and facilities not only to the teachers, but also to the students. Without the minimum ICT equipment and resources with both the students and teachers, online teaching is totally ineffective. Second, there is a need of intensive training to the teachers for making online teaching interactive and meaningful. Whether it is Zoom or Google Meet or Microsoft Teams, they are only the means to reach out to the students and engage them in the learning activity. The essential point is how to make virtual delivery through these means as interactive and lively as done in the physical classroom. Therefore, adequate training is essential for teachers to use these features effectively and efficiently. Third, there is also a requirement for thorough hands-on training to the students as well. This training helps students not only to learn basic requirements of online technology and learning management system, but also help them become more engaged and interactive in the virtual forum. Forth, there is a need for continuous opportunity for updating and upskilling of teachers which should be a core component of inservice professional development programs. Finally, as mentioned above, the curricular materials, including reading and practice materials, should be digitalized

\section{References}

Adams, C. \& van Manen, M. (2018). Teaching phenomenological research and writing. Qualitative Health Research, 27(6): 780-791. DOI: 10.1177/1049732317698960

Braun, V., \& Clarke, V. (2006). Using thematic analysis in psychology. Qualitative Research in Psychology, 3(2), 77-101.

Dai, D. \& Lin, G. (2020). Online home study plan for postponed 2020 spring semester during the COVID-19 epidemic: A case study of Tangquan middle school in Nanjing, Jiangsu province, China. Best Evidence in Chinese Education, 4(2). DOI: 10.15354/bece.20. rp005

Dai, Daxiang and Xia, Xuyue (2020). Whether the school self-developed e-learning platform is more conducive to learning during the COVID-19 pandemic?. Best Evidence in Chinese Education, 5(1):569-580. DOI: 10.15354/bece.20.ar030

Dearing, J. W. (2004). Improving the state of health programming by using diffusion theory. Journal of Health Communication, 9: 21-36.

Dube, B. (2020). Rural online learning in the context of COVID-19 in South Africa: Evoking an inclusive education approach. Multidisciplinary Journal of Educational Research, 10(2): 135-157. DOI: 10.4471/remie.2020.5607

Finlay, L. (2012). Unfolding the phenomenological research process: Iterative stages of "seeing afresh". Journal of Humanistic Psychology, 53(2), 172-201. DOI: $10.1177 / 0022167812453877$ 
Lived Experience of Online Teaching During the COVID-19 Pandemic: Implications... 101

Johnson, N., Veletsianos, G., \& Seaman, J. (2020). U.S. faculty and administrators' experiences and approaches in the early weeks of the COVID-19 pandemic. Online Learning, 24(2): 6-21. https://doi.org/10.24059/olj.v24i2.2285

Mengistie, T.A. (2020) Impacts of COVID-19 on the Ethiopian education system. Science Insights Education Frontiers, 6(1):569-578. DOI: 10.2139/ssrn.3626327

Ministry of Education (2020). School student alternative teaching learning guideline 2077. Author: Kathmandu.

Morgan, H. (2020) Best practices for implementing remote learning during a pandemic. The Clearing House: A Journal of Educational Strategies, Issues and Ideas, 93(3): 135-141. DOI: $10.1080 / 00098655.2020 .1751480$

OECD (2020). A framework to guide an educational response to the COVID-19 pandemic of 2020. Retrieved from https://read.oecd-ilibrary.org/view/?ref=126_126988t631xosohs\&title=A-framework-to-guide-an-education-response-to-the-COVID-19Pandemic-of-2020

Pace,C.,Pettit,S.K.,\&Barker,K.S.(2020).Bestpracticesinmiddlelevelquaranteaching:strategies, tips and resources amidst COVID-19. Becoming: Journal of the Georgia Association for Middle Level Education: 31(1). DOI: 10.20429/becoming.2020.310102

UNESCO (2020). Global monitoring of school closures caused by COVID-19. Retrieved from https://en.unesco.org/COVID19/educationresponse

van Menen, M. (2017). Phenomenology in its original sense. Qualitative Health Research, 27(6): 810-825. DOI: $10.1177 / 1049732317699381$

Xia, J. (2020). Practical exploration of school-family cooperative education during the COVID19 epidemic: A case study of Zhenjiang Experimental school in Jiangsu Province, China. Best Evidence of Chinese Education, 4(2): 521-528. DOI: 10.15354/bece.20.rp003

Xie, Z. \& Yang, J. (2020). Autonomous learning of elementary students at home during the COVID-19 epidemic: A case study of the second elementary school in Daxie, Ningbo, Zhejiang province, China. Best Evidence of Chinese Education, 4(2): 535-541. DOI: 10.15354/bece.20.rp009

Zhang, W., Wang, Y., Yang, L., \& Wang, C. (2020). Suspending classes without stopping learning: China's education emergency management policy in the COVID-19 outbreak. Journal of Risk and Financial Management, 13(3). DOI:10.3390/jrfm13030055

Zhao, N., Zhou, X., and Liu, B., \& and Liu, W. (2020). Guiding teaching strategies with the education platform during the COVID-19 epidemic: Taking Guiyang no. 1 middle school teaching practice as an example. Science Insights Education Frontiers, 5(2):531539. DOI: $10.15354 /$ sief.20.rp005 
Zhou, L. \& Li, F. (2020), A Review of the Largest Online Teaching in China for Elementary and Middle School Students During the COVID-19 Pandemic (May 15, 2020). Best Evidence of Chinese Education, 5(1):549-567. DOI: 0.15354/bece.20.re040

Zhou, L., Wu, S., Li, F., \& Zhou, M. (2020). 'School's out, but class' on', the largest online education in the world today: Taking China's practical exploration during the COVID19 epidemic prevention and control as an example. Best Evidence of Chinese Education, 4(2):501-519. DOI: $10.2139 / \mathrm{ssrn} .3555520$ 